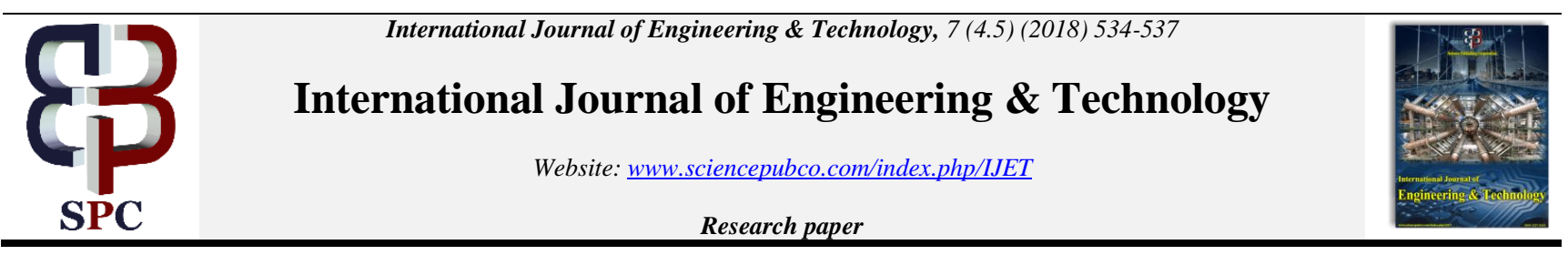

\title{
Electricity generation from living plants using microbial fuel cells
}

\author{
Borker Mohnish $^{1 *}$, Suchithra T. V ${ }^{2}$ \\ ${ }^{1}$ Assistant Professor, Department of Mechanical Engineering, Padre Conceicao College of Engineering, Verna-Goa \\ ${ }^{2}$ Assistant Professor, School of Biotechnology, National Institute of Technology, Calicut-Kerala \\ *Corresponding author E-mail: mohnish.borker12@gmail.com
}

\begin{abstract}
The need for a sustainable source of energy has catered engineers to discover and develop a biological battery known as Plant Microbial fuel cell. This biological battery operates with the help of electrochemically active bacteria in presence of $\mathrm{CO} 2$, sunlight and water. This technique is gaining importance in the field of bioelectricity as it produces clean in-situ energy from living plants without the need to harvest the plant species. Research on these cells have led to the development of various models. One such plant species Setaria faberi was tested for its compatibility in sediment plant microbial fuel cell. Power density of $4.6 \mathrm{~mW} / \mathrm{m} 2$ was obtained when it was tested with cocopeat as a hydroponic media. This paper highlights the suitability of $\mathrm{S}$. faberi in producing sustainable bioelectricity with a hydroponic media.
\end{abstract}

Keywords: Bioelectricity; Hydroponic Media; Plant MFC; Power Density; Rhizodeposition.

\section{Introduction}

A new trend promoting zero emission energy sources states that, $60 \%$ of non-renewable energy sources will be replaced, with wind and solar being the cheapest forms of energy production by 2030 . Owing to conservation strategies and maintaining biodiversity, clean technologies are set to redefine the methods of energy utilization and preservation. India being the seventh largest country in the world has a per capita energy consumption of $1010 \mathrm{kWh}$. At the same time $4.7 \%$ of the geographical landmass in India is wetlands which are not under cultivation. [1].

Biomass being one of the upcoming sources of renewable energy has only $12.83 \%$ contribution towards India's renewable power generation. Biodiesel, Bioethanol as well as bioelectricity have seen a fair share of experimentation when it comes to testing renewable sources of energy. But the main question arises is, whether these sources are sustainable? Land filling, deforestation has always concerned ecologists when it comes to maintaining the biodiversity. 2008 has seen the invention of a new sustainable source of energy production which was neglected for the past years. L. De Schamphelaire et al developed a microbial fuel cell incorporating live plants in the system to provide additional substrate to the microorganisms. [3].

Plant microbial fuel cell (PMFC) or commonly known as biological batteries or solar bio cells, harness power in form of electricity from organic matter of living plants. Organic matter (C6H12O6) generated by the plant during photosynthesis is partly utilised for the plants growth. But, a large considerable amount is excreted out of the roots and into the soil. Microorganisms around the plant roots breakdown these deposits into $\mathrm{CO} 2$, protons and electrons. Inert carbon electrodes are inserted in the soil, completing the circuit to form a powerful biological battery. Figure 1 gives a brief sketch of the working principle of the plant microbial fuel cell.

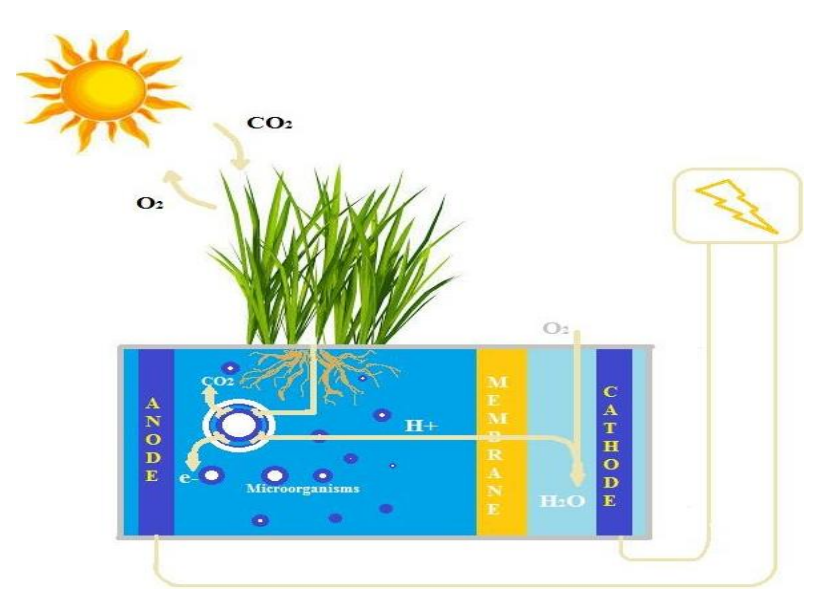

Fig. 1: Working Principle of Plant MFC.

A general consideration is made that the grass species are more suitable for the MFC system. The reason being the roots are fibrous in grass species enabling even distribution of organic matter in the lower soil. Various plant species have been tried in different models. A single chamber sediment type PMFC was tested with rice paddy, which gave $5.75 \mathrm{~mW} / \mathrm{m} 2$ in Japan. [4]. Similarly a dual chamber cylindrical PMFC with Spartina anglica

obtained a high power density of $222 \mathrm{~mW} / \mathrm{m}^{2}$ [5]. A novel tubular design with Glyceria maxima, produced a power density of $60 \mathrm{~mW} / \mathrm{m}^{2}$. [6].

Setaria faberi commonly known as 'fox tail' is a common weed grass in Asia and is found extensively in the natural habitats of Western Ghats as seen in Fig.2. It is a summer weed grass which starts growing towards the end of monsoons and blooms to the fullest by the summers. It is a significant pest, reducing crop production by $13-14 \%$ on an average. It consists of a spikelet that disperses its seeds as a unit, hence the growth in large numbers. This plant spe- 
cies has a high growth rate and is able to survive in tough conditions. The average plant life cycle is around 25 weeks, after which it disperses seeds and dies.

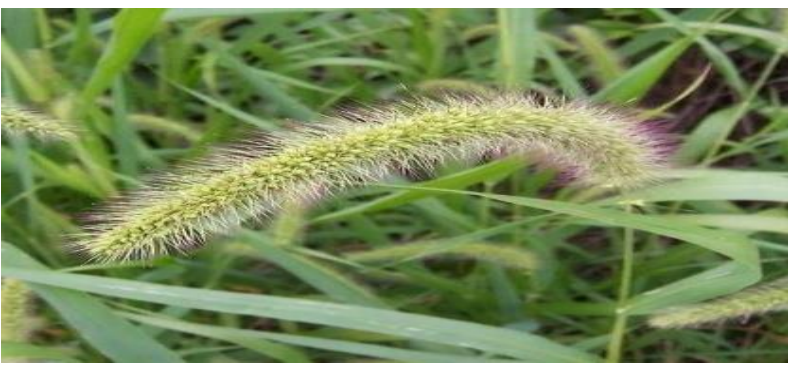

Fig. 2: Setaria Faberi Plant Species.

Considering a sediment type, single chamber PMFC system the need of the proton exchange membrane is eliminated. Here, the plant specimen is grown in the anode chamber, consisting of the anode, while the cathode chamber is eliminated. The cathode is directly exposed to the atmosphere.

\section{Materials and methods}

A sediment type PMFC system is utilised for the S. faberi plant species. As stated earlier, there is no presence of a PEM membrane and a cathode chamber. The electrodes incorporated in the system complete an electrical circuit. Carbon cloth material of dimension $70 \times 90 \mathrm{~mm}$ is utilised as both anode and cathode. Holes are carved on the cathode material to position the plant in the system. The minimum distance maintained between the two is $100 \mathrm{~mm}$. The two electrodes are connected using copper wires to a power harvester or a resistance of desired value.

The gap between the two electrodes is filled with cocopeat, which is a hydroponic media for plant growth. Cocopeat is a natural fibre obtained from coconut, after the coir is separated from the husk. It has high water retention ability, where in it can hold 8-9 times its weight in water. The purpose of using cocopeat is that the clean coir has natural rooting hormones and anti-fungal properties. It has a $\mathrm{pH}$ of 5.2-6.8 which is neutral to slightly acidic which makes it great for alkaline garden soils. Figure 3 gives a brief idea of the setup of the sediment type PMFC.

\subsection{Working of PMFC}

Plant MFC generally operate by exploiting microorganisms in the sub soil region. They provide exudates to these microorganisms which in turn break down the exudate into protons, electrons and carbon dioxide. Thus, they act as natural carbon fixing medium maintaining carbon balance in the atmosphere. Protons are attracted towards the anode which transfers them through a power harvester in an external circuit returning to the cathode. Water is produced at the cathode combining the protons with electrons in presence of oxygen from the atmosphere.

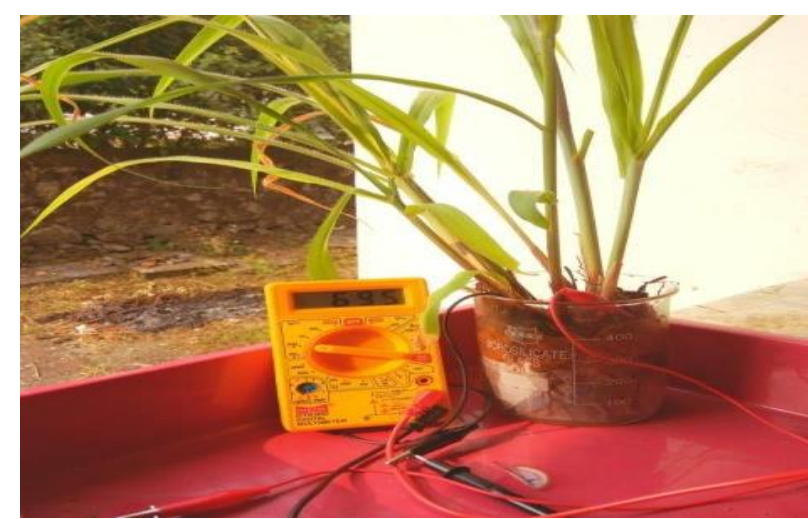

Fig. 3: Sediment PMFC System
The following are the various reactions taking place in the system at the anode and cathode.

Anode:

$2 \mathrm{C} 6 \mathrm{H} 12 \mathrm{O} 6 \rightarrow 2 \mathrm{C} 6 \mathrm{H} 10 \mathrm{O} 6+4 \mathrm{H}^{+}+4 \overline{\mathrm{e}}$

Cathode:

$\mathrm{O} 2+4 \mathrm{H}^{+}+4 \overline{\mathrm{e}} \rightarrow 2 \mathrm{H} 2 \mathrm{O}$

Net Reaction:

$2 \mathrm{C} 6 \mathrm{H} 12 \mathrm{O} 6+\mathrm{O} 2 \rightarrow 2 \mathrm{C} 6 \mathrm{H} 10 \mathrm{O} 6+2 \mathrm{H} 20$

The systems performance is determined by measuring the open circuit voltage and the short circuit current. Polarization curves were obtained to determine the maximum power density using various resistance values. In plant-MFCs the cell potential is a linear function of the maximum theoretical cell potential, current density and the internal resistance. [7]

The plant system was setup exposed to the atmosphere in the National Institute of Technology, Calicut campus where the temperature ranged from $34-25^{\circ} \mathrm{C}$, and the humidity was not controlled. Illumination was through direct sunlight with max solar radiation of up to $950 \mathrm{~W} / \mathrm{m}^{2}$.

\section{Results}

Setaria faberi plant species weighing $200 \mathrm{gms}$ and height of $250 \mathrm{~mm}$ available in and around the campus of NIT Calicut were used for determining its compatibility in a sediment type plant microbial fuel cell. Initially one of the plants was potted within the same soil in which it was available. Incorporating the circuitry along with the electrodes, a value of $220 \mathrm{mV}$ open circuit voltage was obtained. At the same time a short circuit current of $26 \mu \mathrm{A}$ was attained. This initial Voc value was due to various reasons such as omission of nutrients, release of oxygen, conducted through the 'aerenchyma', scavenging the electrons collected at the anode or lack of an adapted anodic microbial consortium. [3]

\subsection{Open circuit voltage (VOC)}

A similar experiment was conducted in cocopeat mixture with same electrode materials and circuit. This system generated a low Voc reading of $162 \mathrm{mV}$. Both the plants were then maintained in their system for an incubation period of 50 days or until their $V_{\text {oc values }}$ reached $400 \mathrm{mV}$. During incubation, the plants were exposed to direct sunlight with max solar radiation of $950 \mathrm{~W} / \mathrm{m}^{2}$

Of the 2 plants, the plant potted in soil showed a gradual increase in its Voc values, reaching $400 \mathrm{mV}$ in 46 days. While that potted in cocopeat had a slower increase initially and attained $400 \mathrm{mV}$ at day 54.

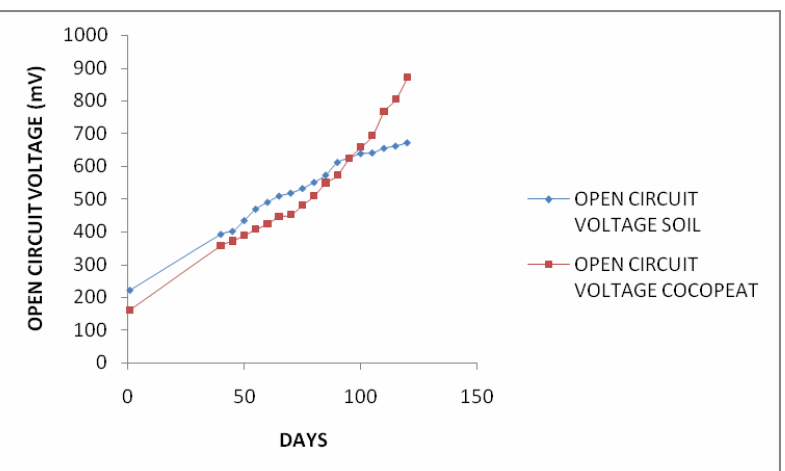

Fig. 4: Plot of VOC for the Two Soil Media at Different Days. 
In the following days, the plant in cocopeat mixture showed a considerable rise in its $V_{\text {oc }}$ value. It increased from $542 \mathrm{mV}$ on day 70 to $873 \mathrm{mV}$ on day 121 . Whereas the soil potted plant was still below $700 \mathrm{mV}$ on day 121. Figure 4 shows the Voc values of the 2 plants. The main aim of this paper is to determine the effectiveness of the cocopeat soil media in the PMFC system with S. faberi.

\subsection{Dependence on sunlight}

Plant MFC systems are known for generating in-situ bioelectricity throughout the day. However the system performance decreases by nightfall due to the absence of necessary sunlight for the photosynthesis. For validating this claim, the cell performance was evaluated during the day, at different hours, determining its dependence on the sunlight. Figure 5 gives the daily variation of the Voc values depicting its dependence on sunlight.

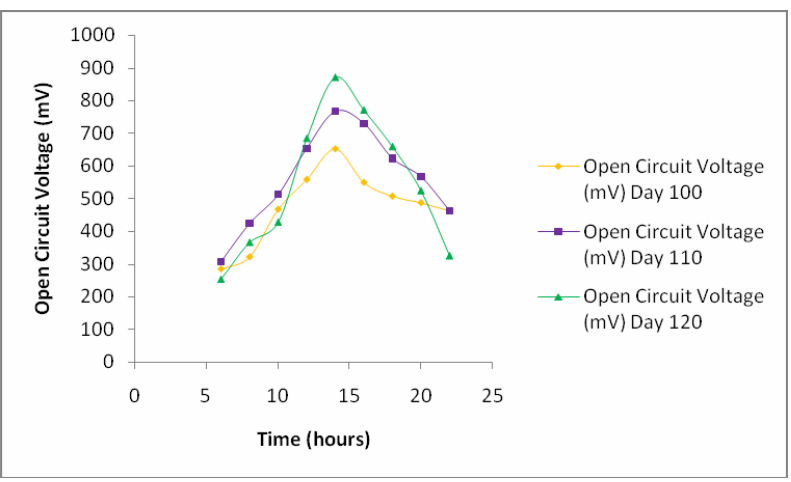

Fig. 5: Open Circuit Voltage Variation at Different Intervals in a Day.

\subsection{Polarization curves}

The polarization curves were obtained for the system with different resistance values. Polarization curves determine the I-V relation of the systems performance. At the same time, it provides the internal resistance of the system. From the I-V plot, the external resistance at which the system provides the maximum power density is the internal resistance of the system. The internal resistance is generally the resistance of the electrodes (anode and cathode), transfer resistance and the ionic resistance [8]. For a sediment type plant MFC, due to absence of a membrane there is high contamination of protons and electrons. This results in higher internal resistance eventually giving lower performance. Figure 6

Gives the polarization curve for the system with S. faberi at different resistance values

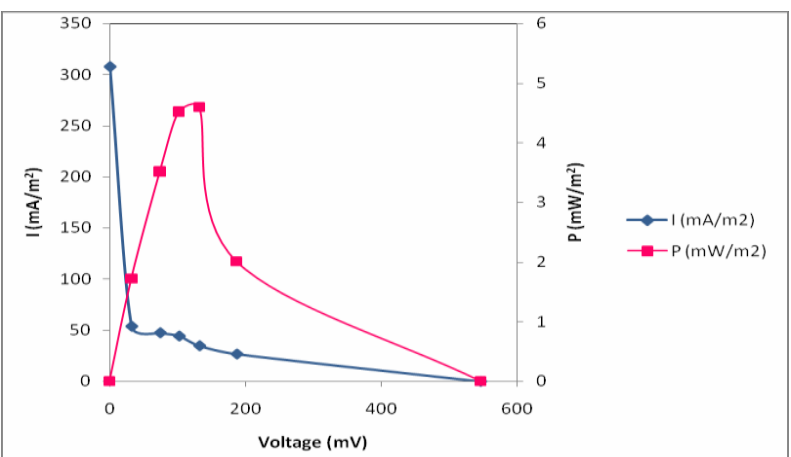

Fig. 6: Polarization Curve for Sediment Type Plant MFC with S Faberi on Day 104.

The above polarization curve gives a maximum power density of $4.6 \mathrm{~W} / \mathrm{m}^{2}$ at the corresponding external resistance of $1500 \Omega$, which is hence the internal resistance of the system. At this $1500 \Omega$, the current densities were measured for determining the variations in the system performance as the plant grows in the system.

\subsection{Series and parallel combinations}

The sediment type plant MFC faces drawback in terms of reduced power output as compared to the other dual chamber models. There have been various investigations to overcome the drawback faced by this system. Being a sediment type PMFC introducing a proton exchange membrane (PEM) to filter the electrons and protons can be beneficial. But PEM is very expensive and the aim is to make a cost effective energy producing bio-cell. Adding acetate solution of $0.1 \mathrm{~N}$ can also improve the systems performance, as it provides the necessary substrate medium, which the microorganisms are deprived of.Performance of the PMFC, can efficiently be improved by chaining two or more bio-cells. To enhance the power density, connecting the plants in series or parallel can be effective. Voltage associated applications can consider series combinations while the parallel connections enhance the current densities. Figure 7 depicts the general series connection of S. faberi in sediment type PMFC.
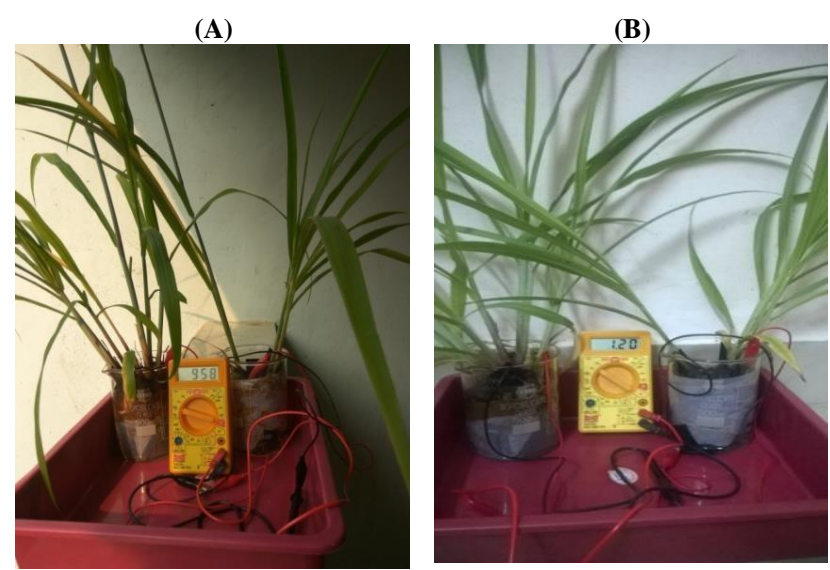

Fig. 7: A) Series and B) Parallel Combinations of Setaria Faberi for Improved Voltage Values.

Polarization curves were obtained for both series and parallel connections by manually taking Multimeter reading at different

Resistances. As can be seen from Fig. 8 the series connection attained a maximum power density of $13.16 \mathrm{~mW} / \mathrm{m} 2$ (anode GA) at $75 \Omega$ while the parallel connection obtained $12.45 \mathrm{~mW} / \mathrm{m} 2$ (anode GA) at $1000 \Omega$.

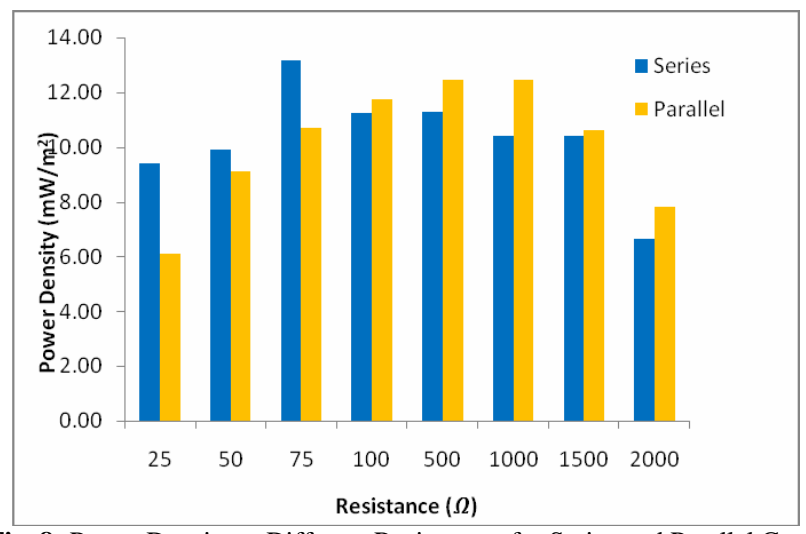

Fig. 8: Power Density at Different Resistances for Series and Parallel Combinations of S. Faberi.

\section{Conclusion}

The sediment type plant microbial fuel cell with Setaria faberi was tested for its performance value in cocopeat as growth medium. The plant was successful in generating a max power density of 4.6 $\mathrm{mW} / \mathrm{m} 2$ with internal resistance of $1500 \Omega$. At the same time it achieved a high current density of $52 \mathrm{~mA} / \mathrm{m} 2$. Parallel and series combinations were tried for enhancing the maximum power density. The series connection attained a maximum power density of 
$13.16 \mathrm{~mW} / \mathrm{m} 2$ (anode GA) at $75 \Omega$ while the parallel connection obtained $12.45 \mathrm{~mW} / \mathrm{m} 2$ (anode GA) at $1000 \Omega$. It is also seen that the internal resistance of the series connections is very low compared to the parallel connection.

This type of technological innovation can be more concentrated at the use of wetlands for power generation. It also finds an application in agricultural industry, as it provides in-situ bioelectricity without harming the plant.

\section{References}

[1] N. Basii, M. Dinesh Kumar, and Status of wetlands in India: A review of extent, ecosystem benefits, threats and management strategies, Journal of Hydrology: Regional Studies. (2014) Vol. 2. PP: 119.

[2] A. Kumar, N. Kumar, P. Baredar, A review on biomass energy resources, potential, conversion and policy in India, Renewable and Sustainable energy reviews. (2015) Vol. 45. PP: 530-539.

[3] L. De Schamphelaire L. V. Bossche, H. Song Dang, Microbial Fue Cells Generating Electricity from Rhizodeposits of Rice Plants, Journal of Environmental Science Technology.(2008). Vol. 42.PP: 3053-3058.

[4] Kaku N Yonezawa N, Kodama Y, Watanabe K. Plant/microbe cooperation for electricity generation in a rice paddy field. (2008).Vol. 79 PP: 43-49.

[5] M. Helder D. Strik, H. Hamelers, Concurrent bioelectricity and biomass production in three Plant Microbial fuel cells Journal of Bioresource Technology (2010) Vol. 101. PP: 3541-3547.

[6] R. Timmers D. Strik, H. Hamelers, Electricity generation by a nove design tubular plant microbial fuel cell, Journal of biomass and bioenergy (2013). Vol. 51. PP: 60-67.

[7] Helder M Strik D., PBTB, Hamelers HVM, Kuijken RCP, Buisman CJN. New plant growth medium for increased power output of the plant-microbial fuel cell, Journal of Bioresource technology. (2012) Vol. 104 PP: 417-23.

[8] Helder M. Strik D., Hamelers M. The flat-plate plant-microbial fuel cell: the effect of a new design on internal resistance, Journal of Biotechnology and Biofuels. (2012) Vol. 5. PP: 1-11. 